\title{
UMA ABORDAGEM DE RELACIONAMENTO NO ENSINO DE BIOLOGIA COM AS QUESTÕES AMBIENTAIS
}

\author{
Rubia Weyrich de Góis ${ }^{1}$, Liane de Souza Weber ${ }^{2}$ \\ ${ }^{1}$ Especialista em Educação Ambiental. \\ 2 Professora/orientadora - Curso de Especialização em Educação Ambiental da UFSM.
}

\section{RESUMO}

A influência cada vez maior da ciência na vida das pessoas exige que elas estejam bem informados para acompanhar as descobertas científicas, avaliar os seus aspectos sociais e participar de forma esclarecida de decisões que dizem respeito a toda a coletividade. Neste sentido, hoje em dia não há nada mais importante para a humanidade do que compreender como a natureza funciona. 0 futuro das pessoas está na dependência de o Homo sapiens aprender a viver sem danificar a máquina da natureza, a ponto de ela não poder mais sustentar a civilização. No entanto, para compreender a máquina da natureza as pessoas precisam entender não apenas como ela opera hoje, mas como foi construída.

Palavras chaves: meio ambiente, doenças pela poluição, educação ambiental e ensino médio

\section{INTRODUÇÃO}

Já é do conhecimento de todos que o planeta Terra está sob sérias ameaças: poluição, aumento da temperatura global, destruição da camada de ozônio, esgotamento de recursos naturais, extinção de espécies entre outros fatores. Tudo isso é decorrência do crescimento da população humana e do desenvolvimento industrial e tecnológico, implementados pelo progresso científico. Felizmente nas últimas décadas muitas pessoas vêm percebendo a necessidade de empenhar-se em um uso mais racional dos recursos naturais.

\footnotetext{
Não adianta chorar a árvore derrubada. Lágrimas não purificam o rio poluído. Dor ou raiva não ressuscita os animais. Não há indignação que nos restitua o ar puro. É preciso ir à raiz do problema. (CHIAVENATO, 1989)
}

Para que se possa compreender cada vez mais e melhor o meio em que o ser humano vive, as interrelações ente o homem e o ambiente, suas expectativas, satisfações e insatisfações, julgamentos e condutas, é de fundamental importância o estudo da educação ambiental. Este estudo deve buscar não apenas o entendimento do que o indivíduo percebe, mas também promover a sensibilização, a consciência, bem como o desenvolvimento do sistema de compreensão do ambiente ao seu redor. Segundo Ferrara (1999) a percepção ambiental é definida como operação que expõe a lógica da linguagem que organiza os signos expressivos dos usos e 
hábitos de um lugar. E nada melhor do que os trabalhos em educação ambiental para efetivar este processo.

Segundo o trabalho de Tuan (1980), existem diversas maneiras de perceber as paisagens, de se construir a realidade através de experiências únicas. Ao entrar em contato com o meio ambiente, as pessoas fazem uso dos cinco sentidos em um processo associado com os mecanismos cognitivos, ou seja, cada indivíduo percebe, reage e responde diferentemente frente às ações sobre o meio. As respostas ou manifestações são, portanto, resultado das percepções, dos processos cognitivos, julgamentos e expectativas de cada indivíduo. Segundo Sandra Faggionato (2005), o homem está constantemente agindo sobre o meio a fim de sanar suas necessidades e desejos.

Muitas das ações sobre o ambiente, natural ou construído, afetam a qualidade de vida de várias gerações. Diversos projetos arquitetônicos ou urbanísticos afetam as respostas dos seus usuários e moradores. E não se falando de respostas emocionais, que dependem do humor ou predisposição do momento, mas da própria satisfação psicológica do homem para com o ambiente.

Frente a todos estes questionamentos, é que a Educação Ambiental se faz tão importante. É através dela que os indivíduos podem ter as respostas das dúvidas às suas ações, e sugerir soluções. Observa-se a importância das escolas, que tem as ferramentas ideais para a introdução dos saberes ambientais. Ferramentas estas que dizem respeito aos indivíduos do sistema educacional, ou seja, as escolas possuem o corpo docente e discente, bem como toda a comunidade escolar que possibilitam as reflexões e discussões. Neste sentido torna-se viável e possível à abordagem das questões ambientais a fim de introduzir de forma eficiente à percepção ambiental.

Claro que não é somente nas escolas que se deve promover este estudo, mas na sociedade como um todo. No entanto, se for feito um bom trabalho dentro das escolas, a sociedade será certamente atingida. Sendo assim, a educação ambiental trabalhada para promover a percepção ambiental não se restringir às escolas, podendo e devendo ir muito além.

Leff (2001, p.191) considera que todos os problemas ambientais enfrentados na atualidade estão no limite. Segundo o autor "A crise ambiental é a crise do nosso tempo. O risco ecológico questiona o conhecimento do mundo. Esta crise apresenta-se como um limite no real, que dá um novo significado e reorienta o curso da história: limite do crescimento econômico e populacional; limite dos desequilíbrios ecológicos e das capacidades de sustentação da vida; limite da pobreza e da desigualdade social."

A cada ano que passa os desafios são maiores, tanto pela diversidade cultural dos alunos bem como o desinteresse dos mesmos por assuntos ligados à Biologia. É importante acender nos alunos o desejo de querer saber mais, de compreender o funcionamento dos ecossistemas, bem como de seu próprio corpo e de como os problemas ambientais podem interferir no bom funcionamento de ambos.

A humanidade depende diretamente da natureza, de onde retira seu alimento e matéria prima industrial a partir de espécies silvestres ou domesticadas. Não há quem não tenha algum tipo de contato diário com qualquer espécie de ser vivo. Moscas, pernilongos, baratas e aranhas habitam as casas, gatos e cachorros rondam os pés de seus donos pedindo carinho. Os alimentos como leite, queijo ou a carne são possíveis graças ao gado, sem falar dos móveis ou mesmo das roupas provindas de espécies vegetais diversas. A manutenção da biodiversidade é ainda fundamental para a saúde humana, com dependência direta da medicina, em suas pesquisas laboratoriais com cobaias como ratos, coelhos entre outros animais. 
A Biologia, como componente curricular assume um papel que transcende os limites dos conteúdos específicos da disciplina, pois possibilita um trabalho de conscientização ecológica através da qual educandos e educadores percebam as demandas do meio ambiente e iniciem, assim, ações para promover a preservação da natureza.

\footnotetext{
"Partindo do pressuposto, compartilhado por vários autores, de que a problemática da degradação ambiental reside no modelo econômico, cultural e antropocêntrico adotado na modernidade, que caminhos poderemos trilhar para um novo modelo de desenvolvimento? Como conscientizar a humanidade para a necessidade da mudança nos hábitos de produção e de consumo? A complexidade da problemática ambiental poderá conduzir o ser humano a uma nova forma de ver e compreender as relações estabelecidas entre sociedade e natureza?" (VILAS-BOAS, 2002, p.6).
}

\section{REFERENCIAL TEÓRICO}

A educação ambiental tem o papel de despertar em todos os seres humanos a consciência de que ele é parte integrada do meio ambiente, visando assim superar a visão antropocêntrica que faz com que o homem sinta-se o centro de tudo e esquece-se da importância da natureza. Já o papel da escola é o de promover ações educativas permanentes, visando o reconhecimento de valores e clarificação de conceitos. Dias (1992) Considera que toda essa importância da temática ambiental e a visão integrada do mundo, no tempo e no espaço, sobressaem-se as escolas, como espaços privilegiados na implementação de atividades que propiciem essa reflexão, pois isso necessita de atividades de sala de aula e atividades de campo, com ações orientadas em projetos e em processos de participação que levem à autoconfiança, a atitudes positivas e ao comprometimento pessoal com a proteção ambiental implementados de modo interdisciplinar.

Mellows (1972) apresentou a educação ambiental como um processo no qual deveria ocorrer um desenvolvimento progressivo de um senso de preocupação com o meio ambiente, baseado em um complexo e sensível entendimento das relações do homem com o ambiente a sua volta. Neste sentido, é de extrema importância que a humanidade conheça as inter-relações que existem entre homem e natureza, para que possa desenvolver habilidades a fim de modificar as suas atitudes em relação ao meio ambiente, visando uma melhoria na qualidade de vida vinculada ao desenvolvimento sustentável.

Segundo experiência realizada por Carvalho (2002), é dentro da escola que a educação acontece. É através da educação que é possível mudar condutas e formar pessoas que, disseminando suas conviç̧ões, trabalharão para uma nova maneira de relacionar-se com o mundo e com os outros.

A escola constitui um espaço privilegiado para o desenvolvimento da Educação Ambiental, na medida em que possibilita a realização de um trabalho de intervenção sistemático, planejado e controlado". "Ao comprometer-se com a incorporação da Educação Ambiental em seu currículo, a escola deverá favorecer a construção de conhecimentos que possibilitem a compreensão da complexidade do meio ambiente e das questões sóciopolíticas e ambientais subjacentes, bem como a formação de atitudes (valores) e habilidades que estimulem a participação de cidadãos no enfrentamento dessas questões, com o objetivo final de melhoria da qualidade de vida e de formação de sociedades sustentáveis. Esses três componentes - conhecimentos, atitudes e habilidades - que influenciam diretamente as práticas sociais, constituem as bases da Educação Ambiental." (PELICIONI, 2002). 
Grande parte do desequilíbrio, para não dizer todo, está relacionado à condutas humanas geradas por atitudes consumistas que geram desperdício, pelo uso inadequado dos bens da natureza. Os seres humanos são responsáveis diretos pelo que acontece a sua volta. Mediante disso, o trabalho educacional é, sem dúvida, um dos mais urgentes e necessários. Parafraseando Dias (1992), a Educação Ambiental deve ser um processo contínuo e permanente, através de ações interdisciplinares globalizantes e da instrumentação dos professores, procurando assim a integração entre escola e comunidade, objetivando a proteção ambiental em harmonia com o desenvolvimento sustentado.

Segundo Amabis e Martho (2004), um dos grandes desafios da humanidade no século XXI é o de modificar o antigo conceito de desenvolvimento de progresso, isto é, de aumento da qualidade de vida sem levar em conta os limites da capacidade de suporte do ambiente em que a espécie humana está inserida. É necessário refletir sobre o impacto que cada uma das pessoas causa sobre o meio ambiente, quanto aos recursos que utilizamos e a destinação do lixo que produzimos. Só assim será possível amenizar o impacto da espécie humana sobre o ambiente terrestre e garantir um local para as futuras gerações.

A biologia ocupa hoje lugar de destaque entre as ciências, principalmente graças ao avanço e à divulgação dos conhecimentos sobre o mundo invisível das células e das moléculas, o que refletiu na melhor compreensão da diversidade da vida e das relações evolutiva entre os organismos. No século XX houve também um grande desenvolvimento da Ecologia, com participação popular cada vez maior nas questões que envolvem o ambiente em que vivemos. Embora fascinante, a Biologia não deixa de ser um desafio para o estudante, pois são muitos os conceitos e processos a serem aprendidos, o que exige dedicação e paciência. (AMABIS; MARTHO, 2004).

Por que estudar educação ambiental dentro da disciplina de Biologia? Talvez o motivo mais importante seja aumentar a capacidade dos seres humanos de entender e de participar do que se passa no seu dia-a-dia. Grande parte do noticiário atual se relaciona a temas biológicos. Quando se fala em clone, em alimentos transgênicos, em testes de DNA, ou no projeto Genoma Humano, é de Biologia que se trata. Quando se descobrem novos tratamentos para as doenças e se vislumbra a cura para o câncer, é também da Biologia que se trata. Num outro nível, discutir a proteção da camada de ozônio, o efeito estufa, a poluição crescente da água e do ar, a extinção de espécies de animais e vegetais, é também falar de temas relacionados à Biologia. (SILVA; SASSON, 2005)

\footnotetext{
Nas últimas décadas, as questões ambientais têm assumido uma importância crescente. A relação com o meio ambiente e a sociedade, como um todo, estabelece-se de forma direta, havendo atualmente uma preocupação cada vez maior sobre este assunto, ficando ultrapassada a concepção de natureza enquanto recurso infinito e inesgotável. [...]Começa a se disseminar uma nova consciência ecológica, em escala planetária, embora há perspectivas diferentes nas diversas sociedades, com concepções diferentes de relacionamento com a natureza, ocasionando conseqüências na esfera ambiental, social, política e econômico (LAZARINI, 2007)
}

Não se pode ver o mundo de uma forma fragmentada. Segundo Capra (1982) a concepção sistêmica vê o mundo em termos de relações e integração, pois os sistemas são totalidades integradas, cujas propriedades não podem ser reduzidas às de unidades menores. Os exemplos de sistemas são abundantes na natureza, todo e qualquer organismo desde a menor bactéria até os seres humanos, passando pela imensa variedade de plantas e animais, podem ser considerados sistemas integrados, ou seja, sistemas vivos. Nesta perspectiva, pode se observar que todos estes 
sistemas naturais são totalidades cujas estruturas específicas resultam das interações e interdependências de suas partes. Parafraseando Capra, embora se possa discernir partes individuais em qualquer sistema, a natureza do todo é sempre diferente da mera soma de suas partes.

A hipótese Gaia, elaborada na década de 1970 acreditava que a Terra era um gigantesco organismo, onde as diferentes formas de vida eram apenas subsistemas componentes. Assim qualquer desequilíbrio em qualquer das espécies, significava um desajuste que de alguma forma influenciaria todo o planeta. Hoje é sabido que todas as formas de vida integram um complexo sistema, que interage com os componentes abióticos. E assim como o meio tem grande influencia sobre os seres vivos, estes também são importantes fatores de alteração do meio. A espécie humana, assim como as demais formas de vida são absolutamente dependentes destas relações, no entanto, diferenciam-se dos outros seres vivos pela sua capacidade de produzir grandes alterações. (TORRES, 2003)

À semelhança do organismo humano, o solo é um sistema vivo que tem de permanecer em estado de equilíbrio dinâmico para ser saudável. Quando esse equilíbrio é perturbado, ocorre um crescimento patológico de certos componentes - bactérias ou células cancerosas no corpo humano, ervas daninhas ou pragas nos campos. A doença sobreviverá e, finalmente, o organismo morrerá ou se converterá em matéria inorgânica. (CAPRA,1982)

A população humana tem crescido num ritmo incrivelmente acelerado nas últimas centenas de anos. Segundo Silva e Sasson (2005) três milhões de pessoas era o numero a 25 mil anos atrás. Hoje são cerca de 6,5 bilhões, e estima-se que a população mundial chegue a 10 bilhões de pessoas antes do ano de 2050. São muitos os fatores que desencadearam esta explosão demográfica, mas o principal deles foi, e continua sendo, a capacidade do homem de explorar os recursos naturais, criar novas e cada vez mais modernas tecnologias, desenvolvimento da ciência e Revolução Industrial. De caçador coletor que havia sido até 10 mil anos atrás, o homem passou a ser agricultor e começou a explorar a terra de forma sistemática. No entanto, não se deu conta dos profundos impactos que passou a causar em seu ambiente.

Segundo Capra (1982) a natureza básica do solo vivo requer uma agricultura que, em primeiro lugar e acima de tudo, preserve a integridade dos grandes ciclos ecológicos. Este princípio estava consubstanciado nos métodos tradicionais de lavoura, os quais se baseavam num profundo respeito pela vida. Sem necessidade do uso de pesticidas, uma vez que os insetos atraídos para uma cultura desapareciam com a outra, e nem fertilizantes químicos, os agricultores enriqueciam seu campo com estrume, devolvendo assim matéria orgânica ao solo para restabelecer o ciclo biológico. Os efeitos a longo prazo da excessiva quimioterapia nas diversas culturas agrícolas provaram ser desastrosas para a saúde do solo e das pessoas, para as relações interpessoais e para todo o ecossistema.

A acelerada explosão demográfica representa um impacto considerável sobre a biosfera. 0 aumento populacional leva a uma maior demanda de alimento, exigindo da agricultura áreas cada vez maiores de cultivo. Há maior demanda por produtos industrializados, implicando maior consumo de energia, conseqüentemente mais construções de hidrelétricas, mais combustíveis são queimados. Quanto mais gente, mais resíduos são produzidos, e os recursos como petróleo e vários produtos minerais tendem a esgotar-se mais rapidamente. A água doce, por causa da poluição e do desmatamento, fica cada vez mais difícil de ser obtida, e tratá-la e cada vez mais caro. $\mathrm{E}$ os mares que pareciam fontes inesgotáveis de alimentos, mais parece a "lixeira do mundo". (AMABIS; MARTHO, 2004) 
Sendo assim, o excessivo crescimento tecnológico criou um meio ambiente no qual a vida se tornou física e mentalmente doentia. Ar poluído, ruídos irritantes, congestionamento de tráfego, poluentes químicos, riscos de radiação e muitos outros fatores de estresse físico e psicológico passaram a fazer parte da vida cotidiana da maioria das pessoas. Além disso, os incalculáveis riscos para a saúde humana não são apenas subprodutos do progresso tecnológico, e sim, são características integrantes de um sistema econômico obcecado com o crescimento e a expansão. E tudo com o intuito de aumentar cada vez mais a produtividade. Além dos riscos para a saúde que podemos ver, ouvir e cheirar, existem outras ameaças ao nosso bem-estar que podem ser muito mais perigosas, porque nos afetarão numa escala muito maior, no espaço e no tempo. A tecnologia humana está deteriorando abruptamente os processos ecológicos que sustentam nosso meio ambiente natural e que são a própria base da nossa existência. (CAPRA, 1982)

Às alterações ambientais advindas das atividades humanas costuma-se aplicar o termo Poluição, que pode ser conceituada como qualquer mudança nas propriedades físicas, químicas ou biológicas de um determinado ecossistema, ocasionada ou não pela ação humana e que acarreta prejuízo ao desenvolvimento das populações, causa desfigurada na natureza e diferentes patologias aos animais, plantas e seres humanos, ou seja, a qualquer ser vivo que faça parte da biodiversidade. Relaciona-se ainda com a presença de microorganismos causadores de doenças (como vírus, bactérias e fungos) ou com a emissão excessiva de calor, som e luz. (FAVARETO; MERCADANTE, 2005)

Segundo Cesar e Sezar (2005), a poluição, seja ela do ar, da água, do solo ou do alimento, pode ser definida como o acréscimo de materiais ou de energia ao ambiente, em quantidades que causem alterações indesejáveis e que possam ameaçar a sobrevivência ou as atividades do ser humano e dos demais organismos. Aos fatores que causam poluição chamam-se poluentes. Em geral, os poluentes são resíduos de atividades humanas essenciais, como a agricultura, a construção civil, os meios de transporte, atividades da indústria, produção de resíduos biológicos como fezes e urina. Quando, porém são jogadas toneladas de todo o tipo de poluente todos os dias no meio ambiente, excede-se a capacidade de assimilação.

Segundo Capra (1982), o ecossistema global e a futura evolução da vida na Terra estão correndo sérios perigos e podem muito bem resultar num desastre ecológico em grande escala. A superpopulação e a tecnologia industrial têm contribuído de várias maneiras para uma grave deterioração do ambiente natural, do qual a humanidade depende completamente. Por conseguinte, a saúde e o bem estar da população estão seriamente ameaçados.

A saúde humana está ameaçada por todos os lados, seja pelo ar, pela água ou pelo solo, as pessoas contaminam-se sem perceber por estes três elementos fundamentais para a existência humana. Em muitos países, aditivos alimentares sintéticos, pesticidas, agrotóxicos, plásticos e outros produtos químicos são comercializados numa proporção atualmente avaliada em mais de mil novos compostos químicos por ano. Assim, o envenenamento químico passa a fazer parte, numa escala crescente, da vida humana. Além disso, a saúde humana através da poluição do ar, da água e dos alimentos constituem meros efeitos diretos e óbvios da tecnologia humana sobre o meio ambiente natural. (CAPRA, 1982)

Sendo assim, a destruição do meio ambiente natural vem acompanhada de um correspondente aumento nos problemas de saúde dos indivíduos. Parafraseando Capra (1982), enquanto as doenças nutricionais e infecciosas são as maiores responsáveis pela morte no Terceiro Mundo, os países industrializados são flagelados pelas doenças crônicas e degenerativas, principalmente problemas cardiovasculares, cânceres e derrames. Sobre os aspectos psicológicos, 
a depressão grave, a esquizofrenia e outros distúrbios de comportamento brotam de uma degeneração paralela da natureza.

Segundo Capra (1982), a obsessão humana pelo crescimento tecnológico e econômico criou um verdadeiro ambiente físico e mental no qual a vida tornou-se extremamente insalubre. $\mathrm{E}$ as formas de contaminação não vêm apenas do ar ou dos compostos químicos que o ser humano está exposto, vêm também do que colocamos em nossa boca e do que ouvimos diariamente. As indústrias alimentícias, a fim de aumentarem seus lucros, passam a fabricar produtos longe das reais necessidades dos seres humanos. Os alimentos fazem parte do nosso dia a dia e são a base para uma vida saudável. Devem ser consumidos de preferência in natura, integrais e isentos de venenos. Parece uma tarefa simples, mas é quase impossível atender a estes requisitos nos dias de hoje, pois os fabricantes de produtos alimentícios adicionam conservantes a eles a fim de aumentar sua vida útil, além de compensar a falta de nutrientes adicionando sabores artificiais e corantes. Os alimentos sintéticos e superprocessados não trazem absolutamente nenhum benefício à saúde humana, pelo contrário trazem inúmeros problemas, que por sua vez são agravados pelo excessivo uso de drogas médicas e não-médicas.

Capra (1982) afirma que uma das mais sérias ameaças, quase totalmente ignorada até recentemente, é o envenenamento da água e do ar por resíduos químicos tóxicos. Diz ainda que o pior de todos os danos, tanto para a saúde humana quanto para o meio ambiente, provém da queima de carvão, cuja fumaça, cinzas, gases e vários compostos orgânicos, são sabidamente tóxicos e cancerígenos. O dióxido de enxofre pode causar graves lesões pulmonares. Além dele tem também a liberação excessiva de óxido de nitrogênio. Uma única usina, ao queimar carvão, pode expelir tanto óxido de nitrogênio quanto várias centenas de milhares de carros. Misturandose com o oxigênio do ar e o vapor de água, estes dois gases sofrem inúmeras reações e convertem-se em ácidos sulfúricos e nítricos, que carregados pelo vento acumulam-se em vários pontos da atmosfera e posteriormente são despejados na terra sob forma de chuva ácida. Esta, ao cair sobre corpos vivos, é altamente mortal.

Segundo Hirata (2006), os combustíveis a base de petróleo emitidos no ar pelos veículos possuem substâncias altamente tóxicas, como hidrocarbonetos e estrógenos, e que ao serem inalados provocam alterações que vão desde simples irritação nos olhos ou nariz até o aumento das chances de cardiopatias e câncer. Os andrógenos liberam substâncias semelhantes aos estrógenos (hormônios femininos), aumentando os níveis desse hormônio no organismo dos homens, comprometendo entre outros problemas, a qualidade do sêmen e o aumento de nascimentos de meninas. Os metais também são inalados facilmente por estarem no ar respirado, provocando cardiopatias, mal de Alzheimer, Parkinson e distúrbios de ansiedade.

Outra ameaça a vida são decorrentes da energia nuclear. Os riscos para a saúde são de natureza ecológica e atuam numa escala extremamente vasta, no espaço e no tempo. As usinas nucleares e o aparelhamento militar liberam substâncias radiativas que contaminam o meio ambiente, afetando logicamente todos os organismos vivos, inclusive o homem. Na maioria das vezes os efeitos não são imediatos, mas acumulam-se gradativamente nos diferentes níveis tróficos. Nos seres humanos, as substâncias contaminam o interior do organismo com muitas conseqüências a médio e longo prazo. O câncer, por exemplo, tende a desenvolver-se depois de dez a quarenta anos, e as doenças genéticas podem aparecer em gerações futuras. Sabe-se que as radiações ambientais de baixo nível são absolutamente normais, e incidem sobre a Terra há bilhões de anos, provenientes de fontes naturais, mas aumentá-las significa jogar com a saúde humana (CAPRA, 1982). 


\section{CONSIDERAÇÕES FINAIS}

Mesmo que a humanidade tenha tomado consciência dos problemas gerados pelos diferentes tipos de poluição, ainda falta muito que avanças no sentido de as pessoas terem atitudes diárias e constantes. Neste sentido é de se desejar que a humanidade exerça sua capacidade de controle sobre o crescimento de suas populações, sobre o uso adequado da terra, sobre o consumo dos recursos não-renováveis e sobre a destinação que dá a seus detritos, de forma menos negligente do que tem feito até hoje.

E devido a sua capacidade única de refletir, conhecer e prever, é que o ser humano tem o dever de controlar seu ambiente e seu comportamento. $O$ ser humano já possui um conhecimento razoável de seu patrimônio genético e controla, num certo nível sua própria evolução. É justamente por causa de sua capacidade especial de raciocinar, que sua responsabilidade torna-se tão grande.

Não importa o tamanho das ações, grandes ou pequenas, qualquer atitude é válida. Pode se observar isto ao se ler revistas científicas relatando experiências bem sucedidas ou sugestões interessantes para serem aplicadas. A televisão e a internet também são meios importantes de divulgação de ações em relação ao meio ambiente. A maioria dos autores de livros didáticos do ensino médio já vem mostrando há muito tempo à preocupação com os assuntos ambientais, o que pode ser observado nas leituras complementares disponíveis em seus capítulos.

\section{BIBLIOGRAFIA}

AMABIS, José Mariano; MARTHO, Gilberto Rodrigues (2004). Biologia - volumes 1, 2 e volume 3 - $2^{\text {a }}$ ed. - São Paulo : Moderna.

CAPRA, Fritjof. O Ponto de Mutação. São Paulo: Ed Cultrix (Trad. Álvaro Cabral)

CARVALHO, Maria Bernardete S da S (2002). GRUPO DE EDUCAÇÃO AMBIENTAL - Universidade Federal de Juiz de Fora. Disponível em <http://www.gea.ufjf.br>. Acesso em: agosto de 2009

CHIAVEnATO, J.J. O Massacre da Natureza. São Paulo: Moderna, 1989 (coleção Polêmica)

DIAS, G. F. Educação Ambiental: princípios e práticas. São Paulo, Gaia, 1992.

FAGgIONATO, S. Percepção ambiental. Disponível em: <HTTP://www.educar.sc.usp.br/textos>. Acesso em outubro de 2009.

FAVARETO, José Arnaldo; MERCADANTES, Clarinda. Biologia - volume único - 1a Ed. - São Paulo: Moderna, 2005

FERRARA, Lucrecia D’Alessio. Olhar Periférico: Informações, Linguagenm, Percepção Ambiental. São Paulo: Edusp, 1993

LAZARANI A.M. Rosmari. FLORA E FAUNA. O Homem e o Meio Ambiente. Disponível em:<http://www.floraefauna.com/meioambiente/homem ambiente.htm>. Acesso em junho de 2009.

LEFF, E. Epistemologia ambiental. São Paulo: Cortez, 2001. 240p.

MELLOWS, apud DIAS, Genebrando Freire Dias. Educação Ambiental - Princípios e Práticas. São Paulo, Gaia 1992 
PELICIONI, A. F. Educação e Ambiental na escola - uma experiência de sucesso. Disponível em: <http://www.neoambiental.com.br> Acessado em: julho de 2009.

SILVA, Júnior, César da; SASSON, Sezar (2005). Biologia - volumes 1, 2 e 3 - $3^{\text {a }}$ série - genética, evolução e ecologia $7^{\text {a }}$ ed. - São Paulo : Saraiva

TORRES, Patrícia Lupion, org. Uma leitura para os temas transversais: ensino fundamental/ Patrícia Lupon Torres /e/ Regina Bochniak organizadoras. - Curitiba: SENAR-PR, 2003.

TUAN, Yi-Fu (1980) Topofilia - Um Estudo da Percepção Atitude e Valores do Meio Ambiente. São Paulo/Rio de Janeiro: Ed Difel (Trad. Lívia de Oliveira)

VILAS-BOAS, D. A. C. Uma experiência em educação Ambiental: Re-Desenhando o espaço e as Relações Escolares. 2002. 65f. Dissertação (Mestrado) - PRODEMA (Programa de Desenvolvimento e Meio Ambiente), Universidade Federal da Paraíba, João Pessoa, 2002. 